\title{
A Comparative Analysis and Evaluation of the DGRF-85 and IGRF-90 Candidate Models
}

\author{
John M. QuinN, Donald L. SHIEL, Steven FABER, and Joy A. ConRAD \\ U.S. Naval Oceanographic Office, Geopotential Division, Stennis Space Center, MS 39522-5001, U.S.A.
}

(Received November 27, 1991; Revised June 26, 1992)

\begin{abstract}
Candidate models for the Definitive Geomagnetic Reference Field (DGRF) main field model at the 1985.0 epoch, as well as candidate models for the International Geomagnetic Reference Field (IGRF) main field model at the 1990.0 epoch along with the corresponding secular variation models at the 1992.5 epoch were evaluated against each other, and against data observations from both Project MAGNET aeromagnetic data and recently obtained Polar Orbiting Geomagnetic Survey (POGS) satellite data.

Models for the 1985.0 epoch show some regional differences in model by model comparisons but, in general, are quite similar. All models agree well with the observed Project MAGNET data, which in this study involved 29,535 globally distributed observations collected between 1985.0 and 1989.9.

Models for the 1990.0 epoch showed greater differences that were still regional rather than global in nature. The same was true for the corresponding 1992.5 secular variation models. The main field and secular variation models, in addition to direct comparisons against each other, were also compared against POGS total intensity data at the epoch 1991.1386. The US/UK models have problems in the south central Pacific, while the IZMIRAN models have problems in the south Atlantic. Recommendations based on the results of the model evaluations are summarized in Table 4.
\end{abstract}

\section{Introduction}

Candidate main geomagnetic reference-field models were solicited for Epochs 1985.0 and 1990.0, while candidate secular variation geomagnetic reference-field models were solicited for Epoch 1992.5 by the International Geomagnetic Reference Field (IGRF) working group, which is sponsored by the International Association of Geomagnetism and Aeronomy (IAGA). Responding to this solicitation, models for Epochs 1985.0 and 1990.0 were supplied by the National Aeronautics and Space Administration (NASA), jointly by the U.S. Naval Oceanographic Office (NAVOCEANO) and the British Geological Survey (BGS), IZMIRAN (USSR), and the U.S. Geological Survey (USGS). Secular variation models for the 1992.5 Epoch were supplied by IZMIRAN, USGS, and jointly by NAVOCEANO and BGS. NASA supplied two main field models for both the 1985.0 and 1990.0 epochs which are distinguished by the lack of data from the Dynamics Explorer-2 (DE-2) (LANGEL et al., 1988), which was distributed to all modelers by Dr. Robert Langel of NASA and the inclusion of DE-2 data, the former being designated the NASA-S model, while the latter being designated as the NASADS model. The joint NAVOCEANO-BGS models are referred to as the US/UK models. A summary of the models submitted is given in Table 1. Details of these models are presented 
Table 1. Candidate models submitted.

\begin{tabular}{lccc}
\hline Institution & & Epoch & \\
\cline { 2 - 4 } & $1985.0 \mathrm{MF}$ & $1990.0 \mathrm{MF}$ & $1992.5 \mathrm{SV}$ \\
\hline IZMIRAN & Yes & Yes & Yes \\
US/UK & Yes & Yes & Yes \\
USGS & Yes & Yes & Yes \\
NASA-S & Yes & Yes & No \\
NASA-DS & Yes & Yes & No \\
\hline
\end{tabular}

as separate articles in this same issue of the journal.

The comparative analysis/evaluation of the candidate models consisted of three parts:

a) A qualitative comparison of the Total Intensity (TI), Declination (DEC), and Inclination (DIP) components of the magnetic field for all model combinations at both the 1985.0 and 1990.0 epochs plus a similar analysis on the rates of change of these components as indicated by the 1992.5 secular variation models as well as the implied 1987.5 models which can be computed by differencing the main field models supplied by each institution at the two main field epochs. A total of 165 charts were generated and examined for global and regional inconsistencies.

b) A statistical analysis of the 1985.0 epoch models with respect to post-1985.0 Project MAGNET total intensity data using the implied 1987.5 secular variation models.

c) A qualitative and statistical analysis of the 1990.0 epoch main field models and their corresponding 1992.5 secular variation models with respect to a small set $(52,689$ observations) of recently obtained Polar Orbiting Geomagnetic Survey (POGS) satellite total intensity data collected between February 2, 1991 and March 2, 1991. The USGS 1992.5 candidate secular variation model was applied to the two NASA 1990.0 main field models for this purpose since they had no corresponding secular variation models of their own.

\section{Data Sets}

The Project MAGNET data used in this analysis consist of high altitude ( $\geq 15,000$ feet) survey data collected by the Naval Oceanographic Office (NAVOCEANO) during the period 1985 through 1989. Details of this data set (e.g., Project ID, Flight \#, dates flown and flight statistics) are summarized by QUINN et al. (1991). This data set as well as all other high level Project MAGNET survey data are available through the National Geophysical Data Center (NGDC) in Boulder, Colorado. The Project MAGNET data set was one of the few vector magnetic data sets, if not the only vector magnetic data set to become available since MAGSAT. Details of Project MAGNET instrumentation, calibration, and survey techniques are described by Ms. R. J. COLEMAN in a NASA technical report edited by Dr. R. A. Langel (1992).

The Polar Orbiting Geomagnetic Survey (POGS) satellite, launched April 11, 1990, is a low cost effort to secure scalar magnetic data to support the 1995 epoch magnetic field modeling efforts. This satellite is sponsored by the U.S. Navy, the Space Test Program (STP), the Office of Naval Research, and the Naval Oceanography Command. The satellite is operated by NAVOCEANO. 
1991 POGS data, covering the 20-day period from February 10 through March 11, 1991, were used to evaluate the IGRF-90 candidate models. Delays in sending 1990 data to NGDC are the results of initial difficulties in calibrating the onboard POGS clock. This problem was solved in January 1991. Other lingering calibration issues have just recently been resolved. Delays in resolving these calibration issues have been more logistical than technical.

The Navy's TRANET system tracks the POGS satellite's two beacons. The Defense Mapping Agency (DMA) processes this tracking data to produce an orbit ephemeris with a spherical estimated error of less than 75 meters. The POGS experiment magnetometer, which was built by NASA, is a triaxial fluxgate similar to the ones built by NASA for the Defense Meteorological Satellite Program (DMSP) but which has been specially modified to reduce thermal drift to less than $50 \mathrm{nT} / \mathrm{yr}$. Since no provision has been made for inflight calibration of the magnetometer, estimating the actual thermal drift will be very difficult. The magnetometer is located at the tip of an 8-foot non-magnetic boom. A $7 \mathrm{nT}$ magnetic bias, generated by electronic instruments within the body of the satellite, can be sensed by the magnetometer along the Z-axis of the spacecraft. The spacecraft itself was built by Defense Systems, Incorporated (DSI). Due to the lack of accurate attitude determination devices on the spacecraft, the magnetometer is essentially operated as a scalar instrument. It has a resolution of $2 \mathrm{nT}$. The spacecraft is gravity gradient stabilized and transmits data to three ground stations located at Fairbanks, Alaska; Bay St. Louis, Mississippi; and Keflavik, Iceland. POGS has been in operation for nearly two years. Its maximum estimated life, which is battery limited, is 3 years. The batteries are powered by 52 solar panels which surround the exterior of the spacecraft. The effective data sample rate is one sample per ten-second interval. The satellite has a mean orbital altitude of $688 \mathrm{~km}$, a period of 98.61 minutes, an inclination of 89.88 degrees and an eccentricity of 0.007895 (i.e., the orbit is almost perfectly circular). The orbit is not sun synchronus and therefore covers all local times.

\section{Analysis}

Declination and inclination differences among competing main field models proved to be less revealing than the total intensity differences. This was also true of the rates of change of these components for the competing secular change models. Figures 1(a) through 1(d) show a selected sample of the total intensity differences for the 1985.0 epoch. Figures 2(a) through 2(d) show a selected sample of the total intensity differences for the 1990.0 epoch. Figures 3(a) through 3(c) show a comparison of total intensity secular variation differences for Epoch 1992.5 .

At the 1985.0 epoch, all models show good agreement in the Northern Hemisphere. In the Southern Hemisphere, both NASA models agree well with the USGS model and consequently also with each other, while the US/UK model deviates noticeably from the USGS model southwest of Australia. The IZMIRAN model deviates noticeably in the south central Atlantic. These differences can be traced to secular variation model errors at the 1982.5 and 1987.5 epochs due to a lack of observatory data in those areas and to differences in modeling procedure. The NASA main field and secular variation models were derived together, whereas, the USGS, IZMIRAN, and US/UK main field and secular variation models were derived separately. The former procedure allows survey data to supplement the observatory data in the secular variation model computation, whereas, the latter does not. Consequently, the latter method has less control in areas where observatory data is sparse. For this reason, the 


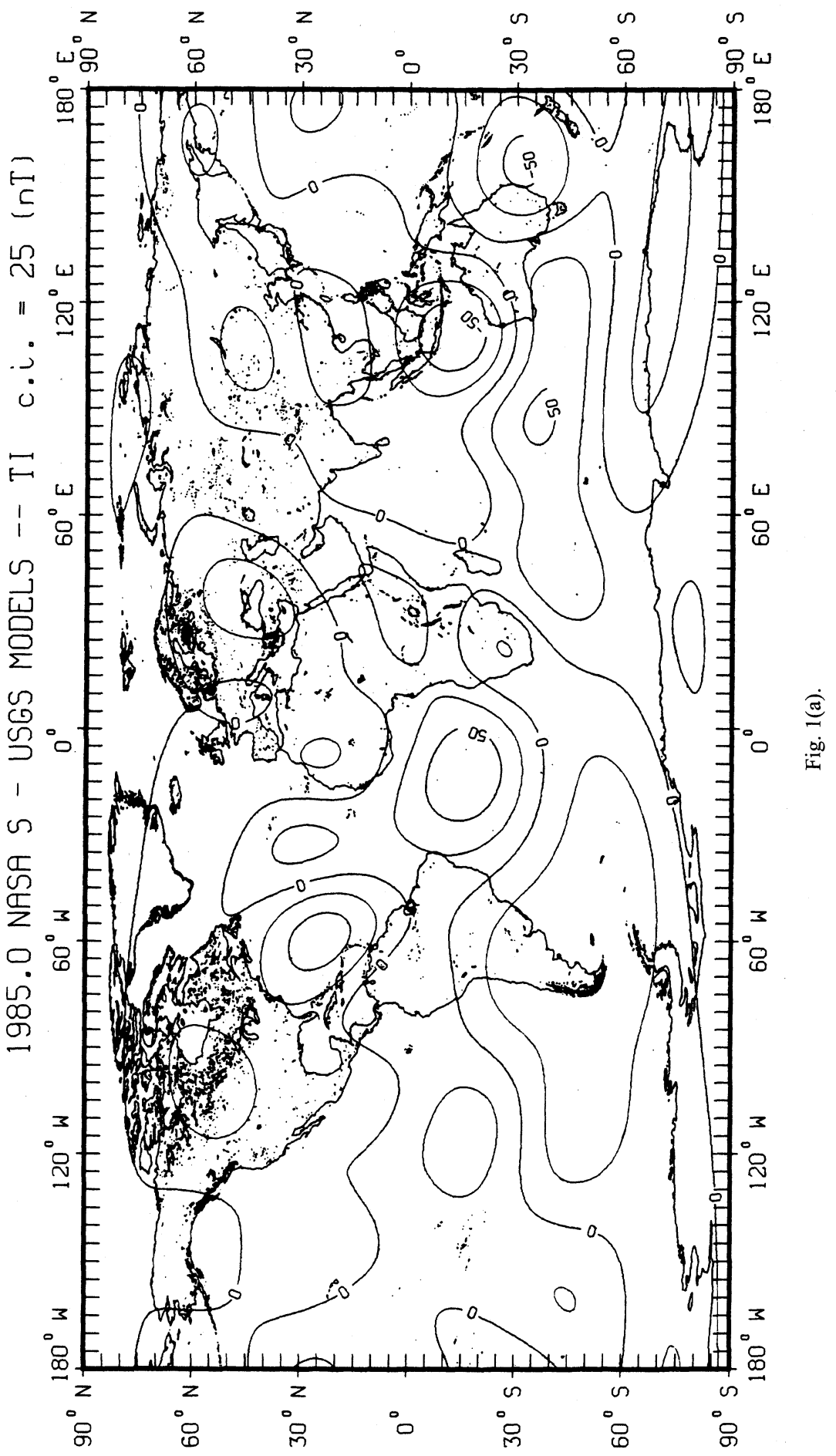




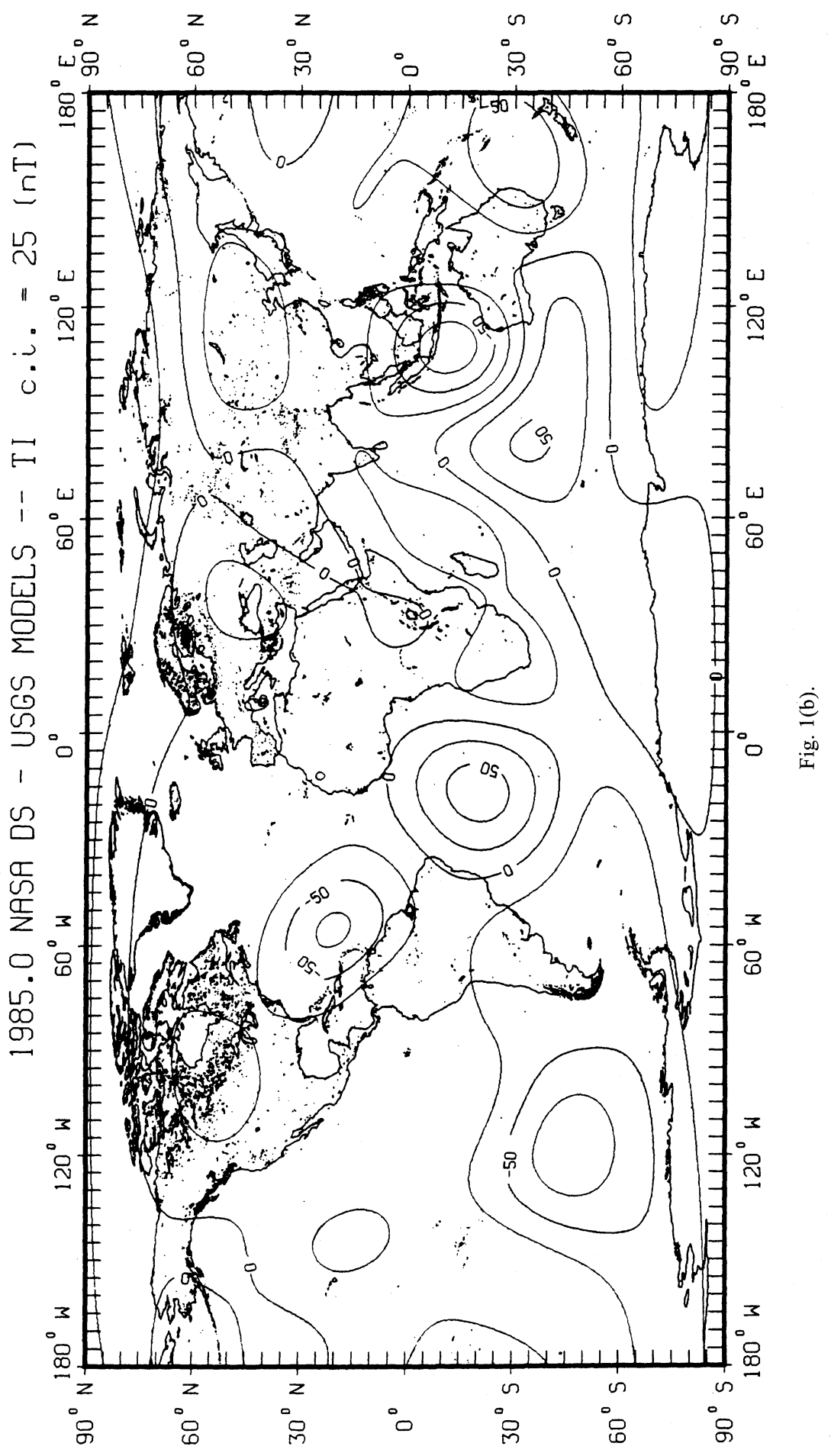




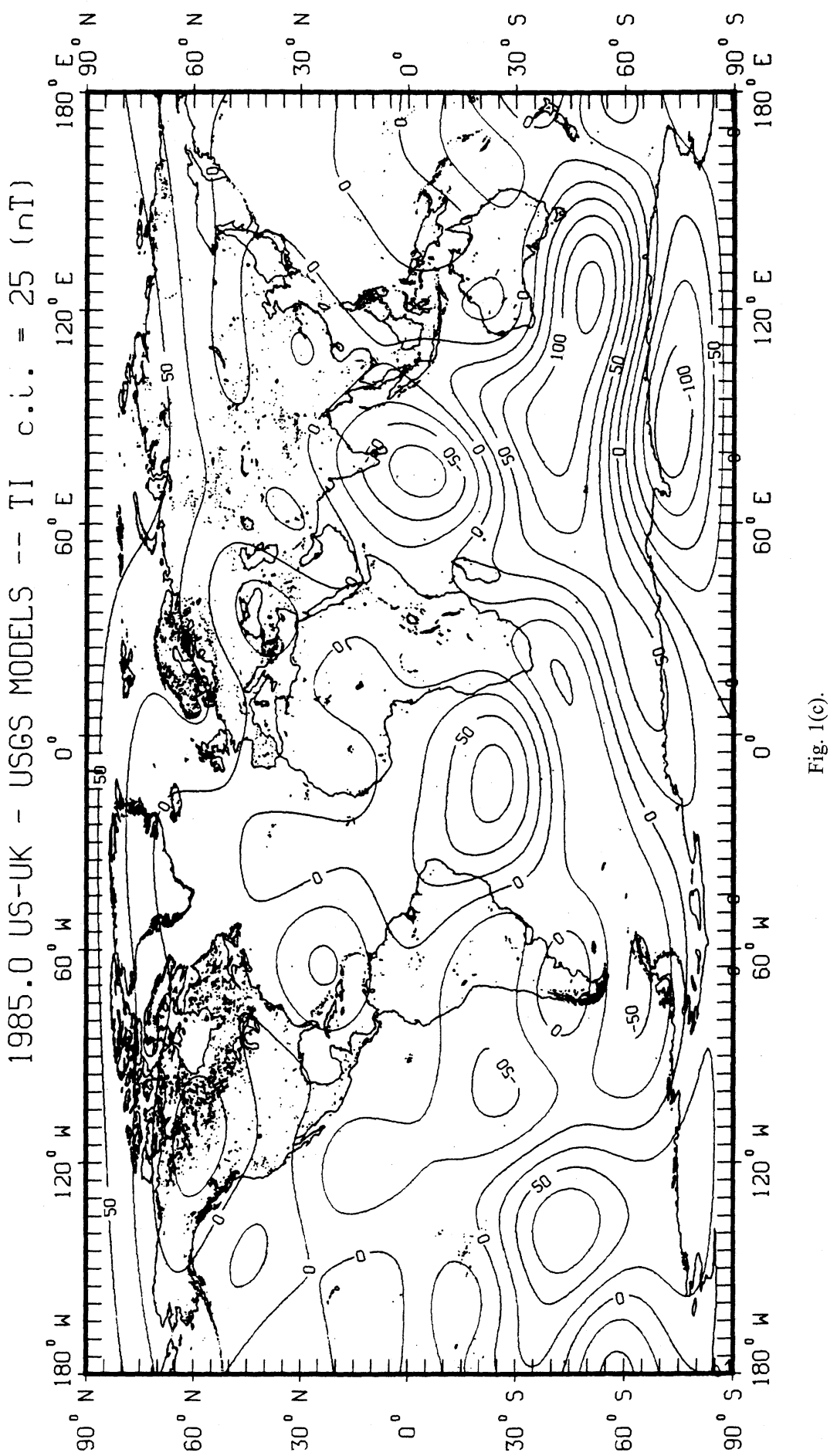




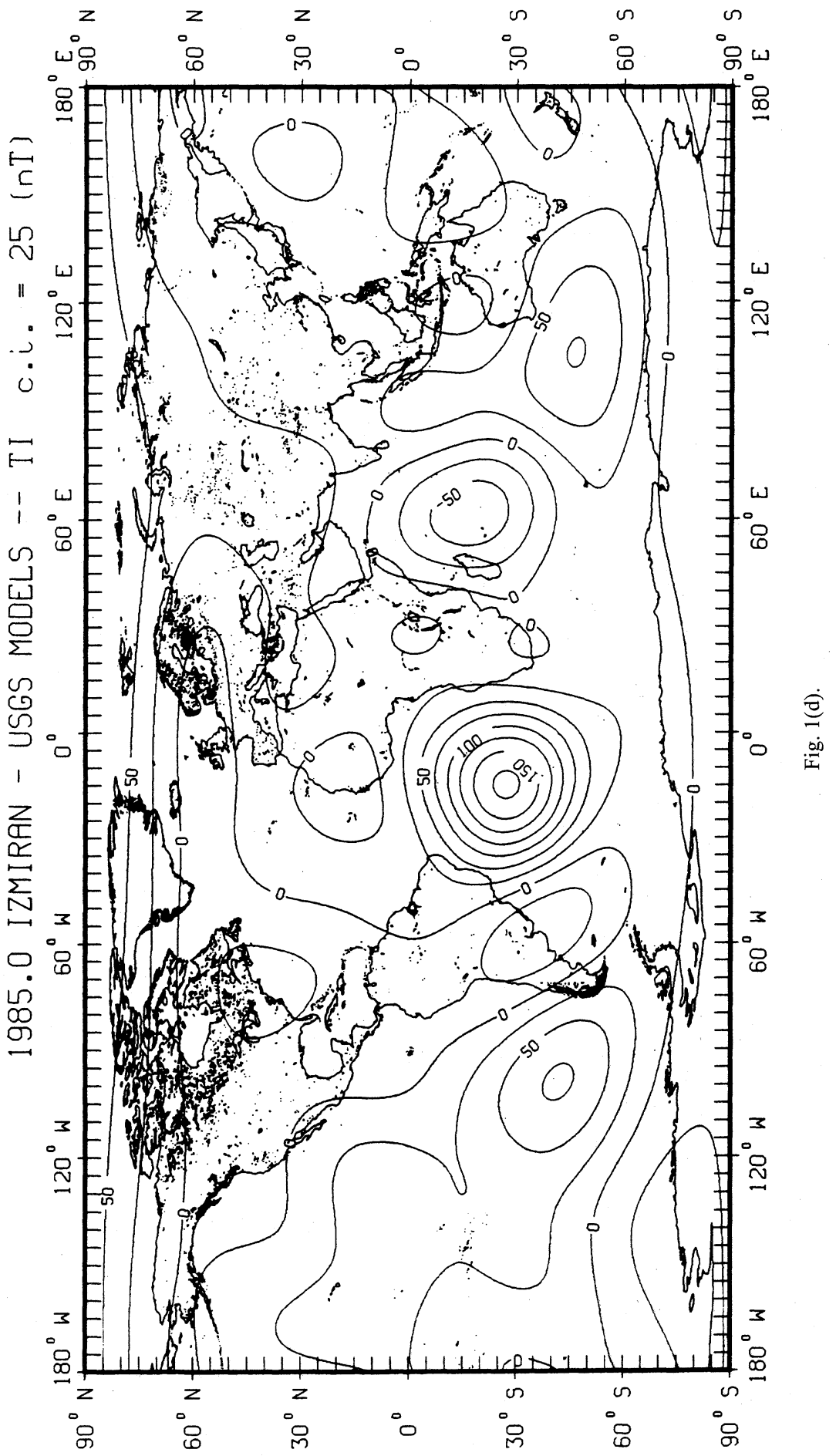




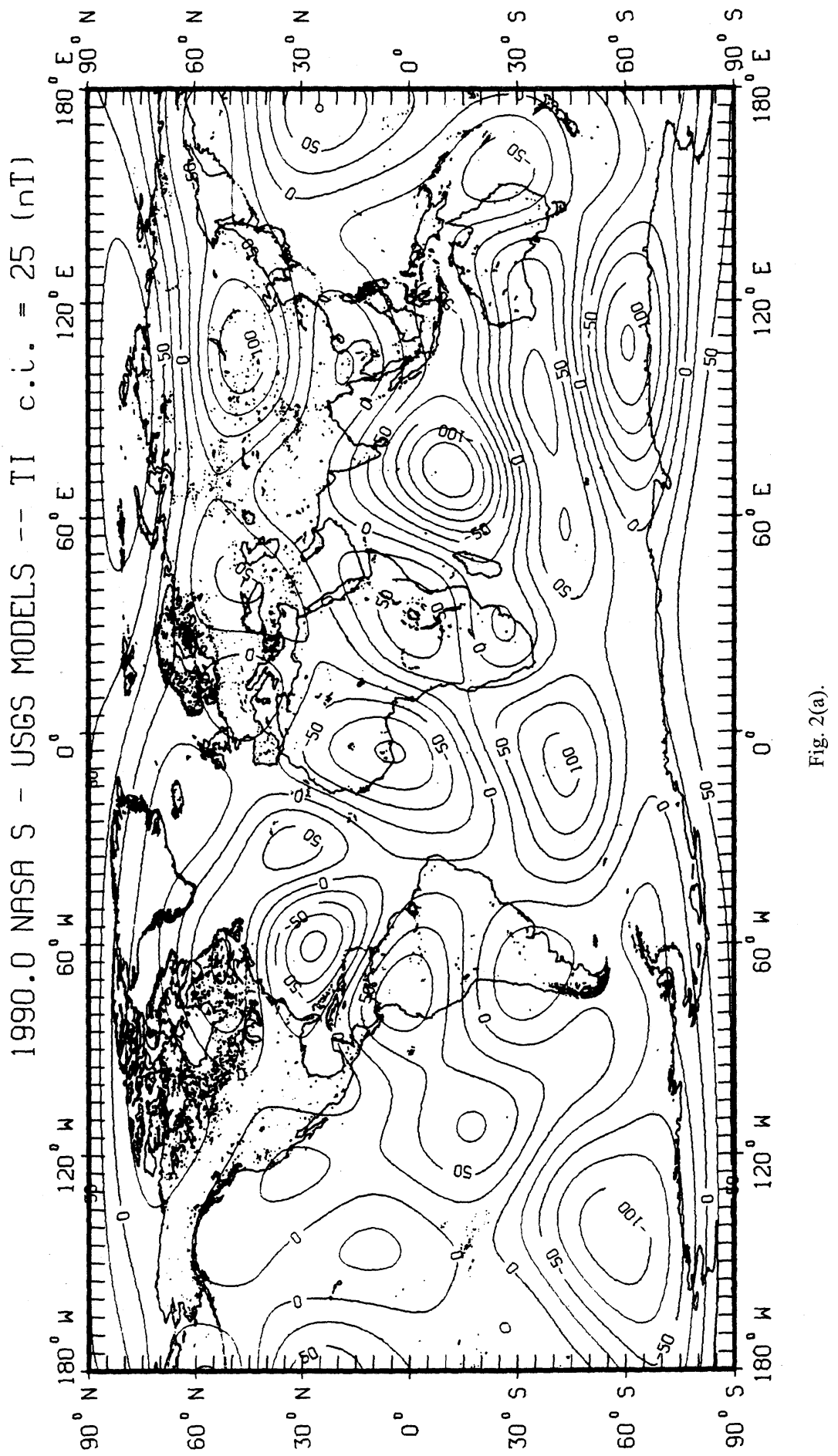




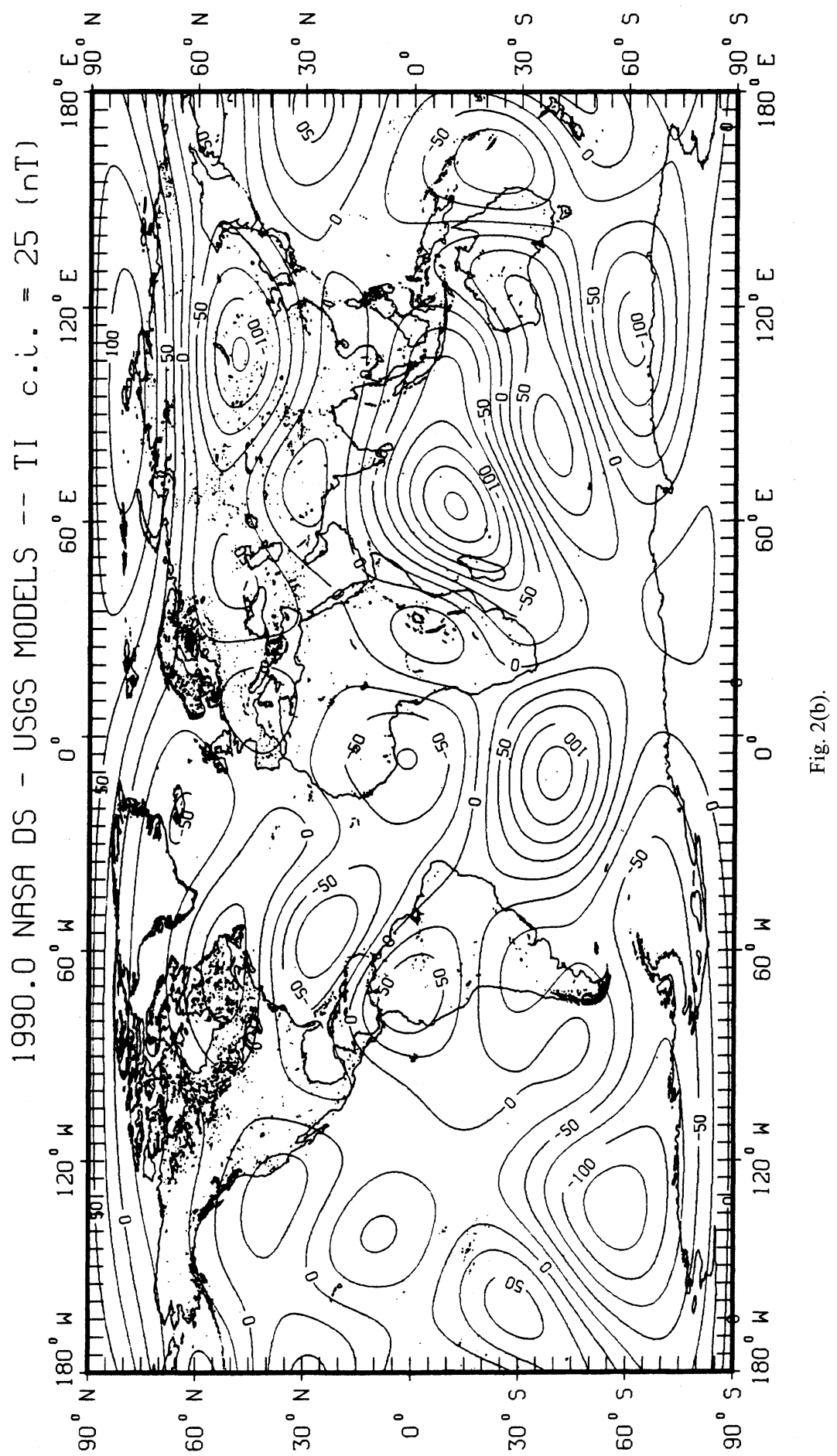




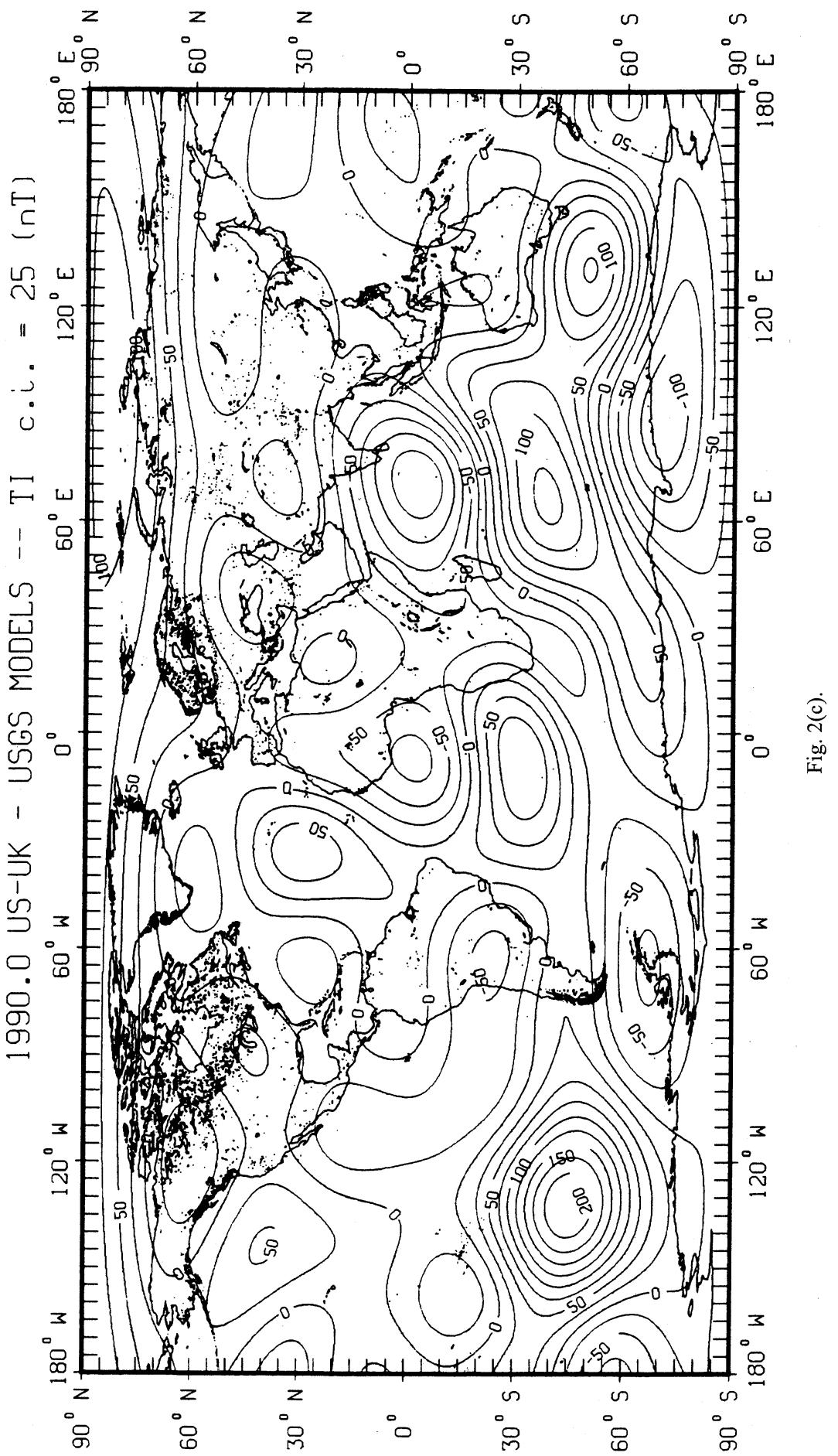




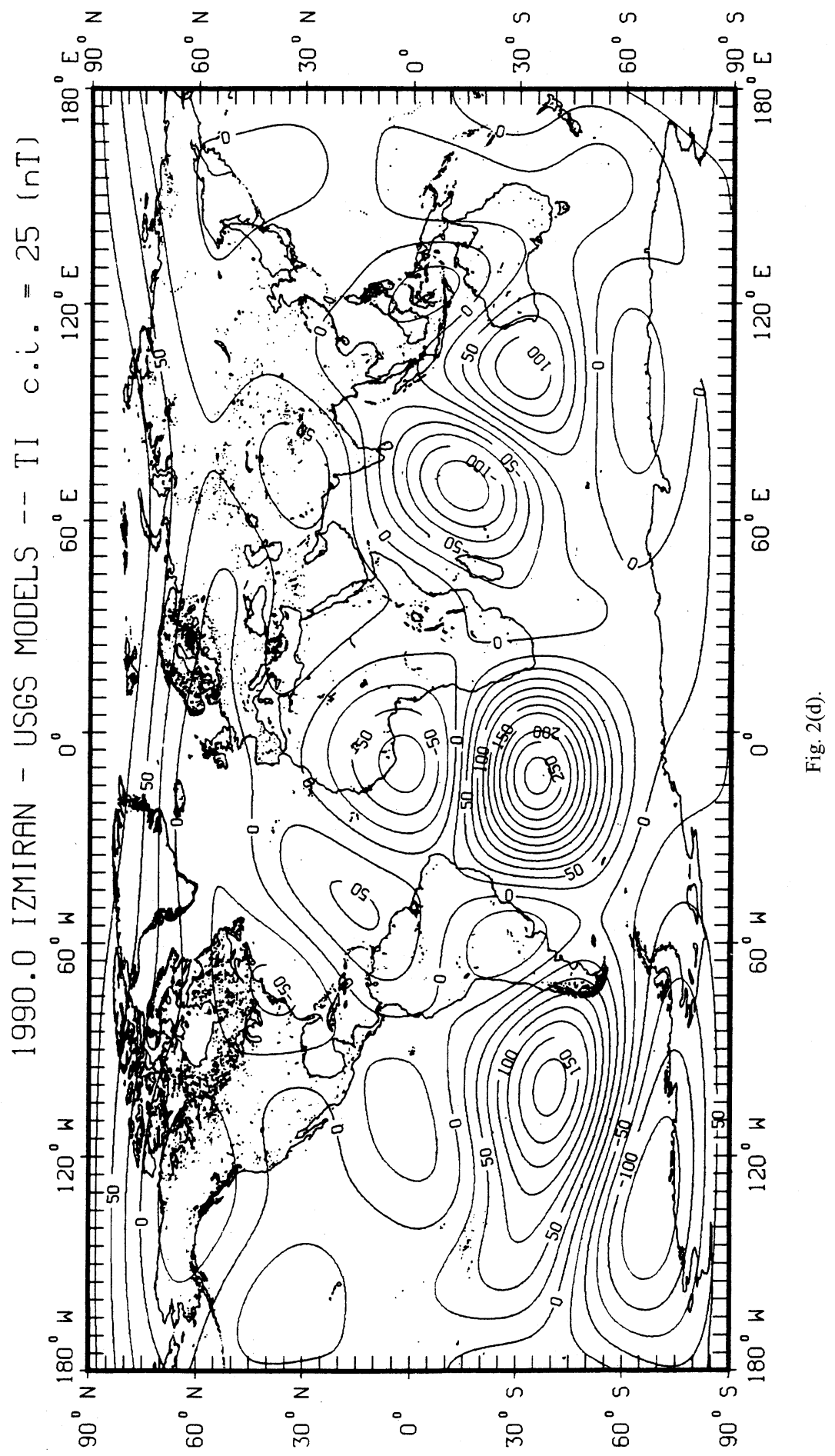




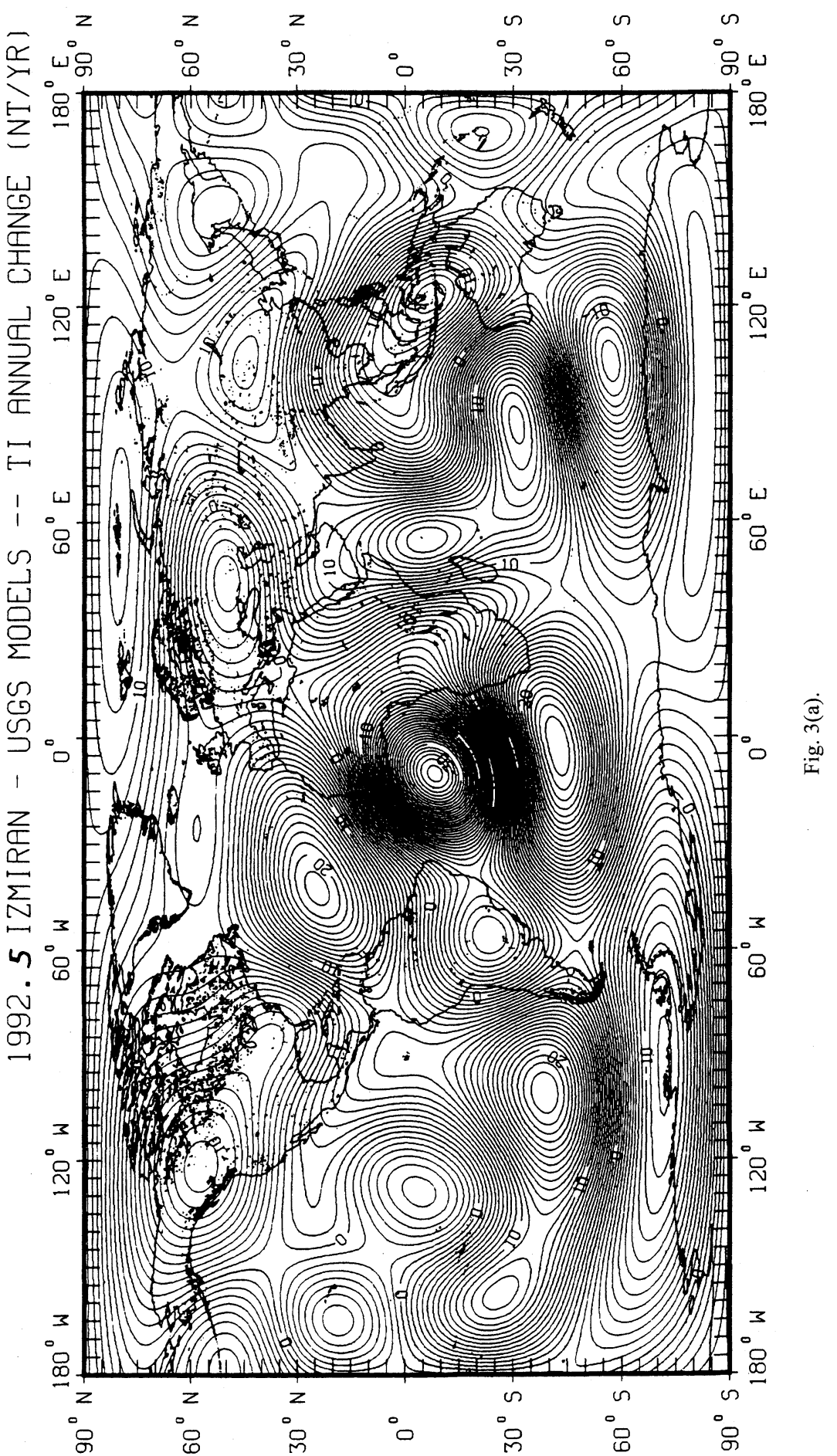




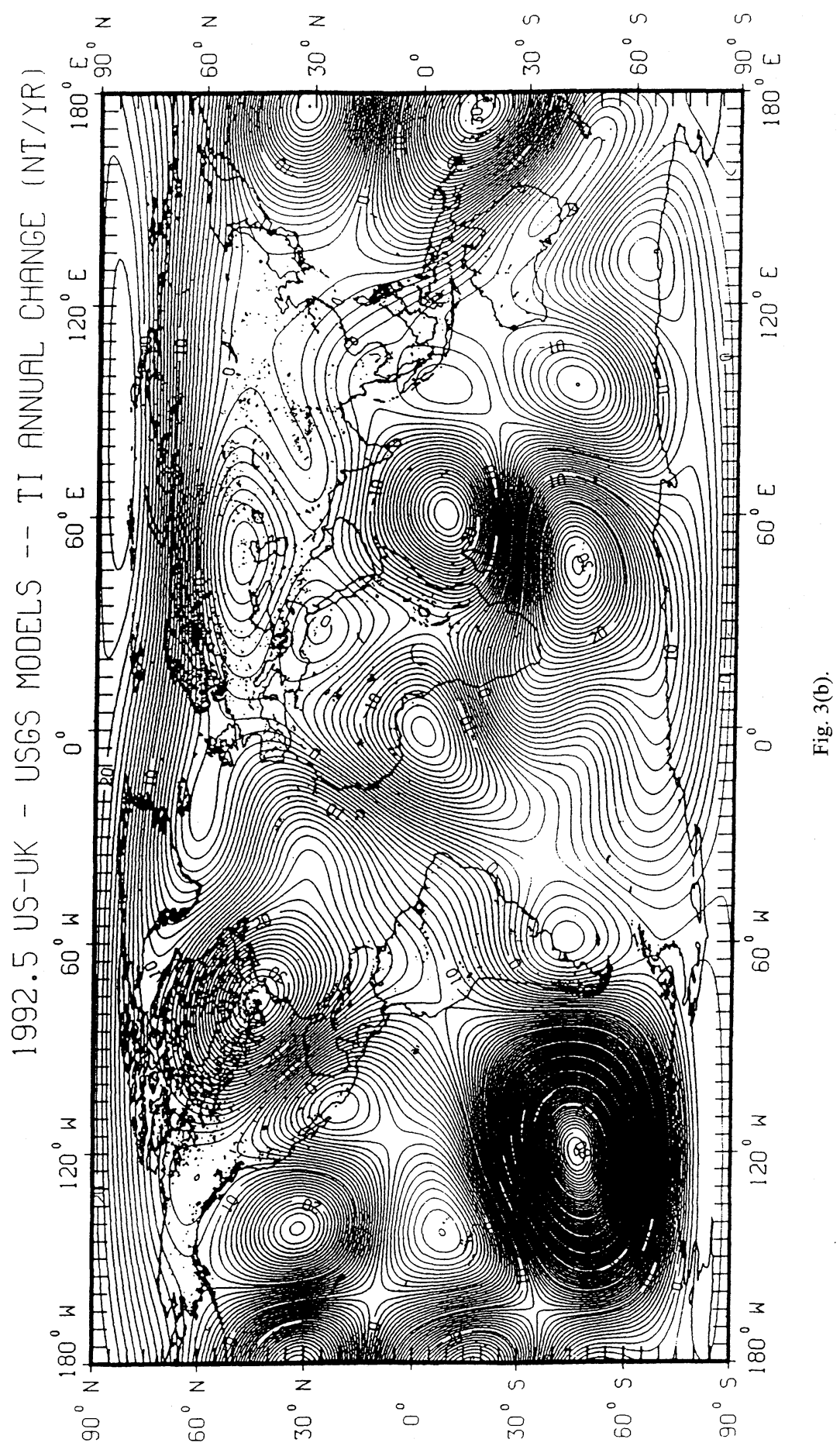




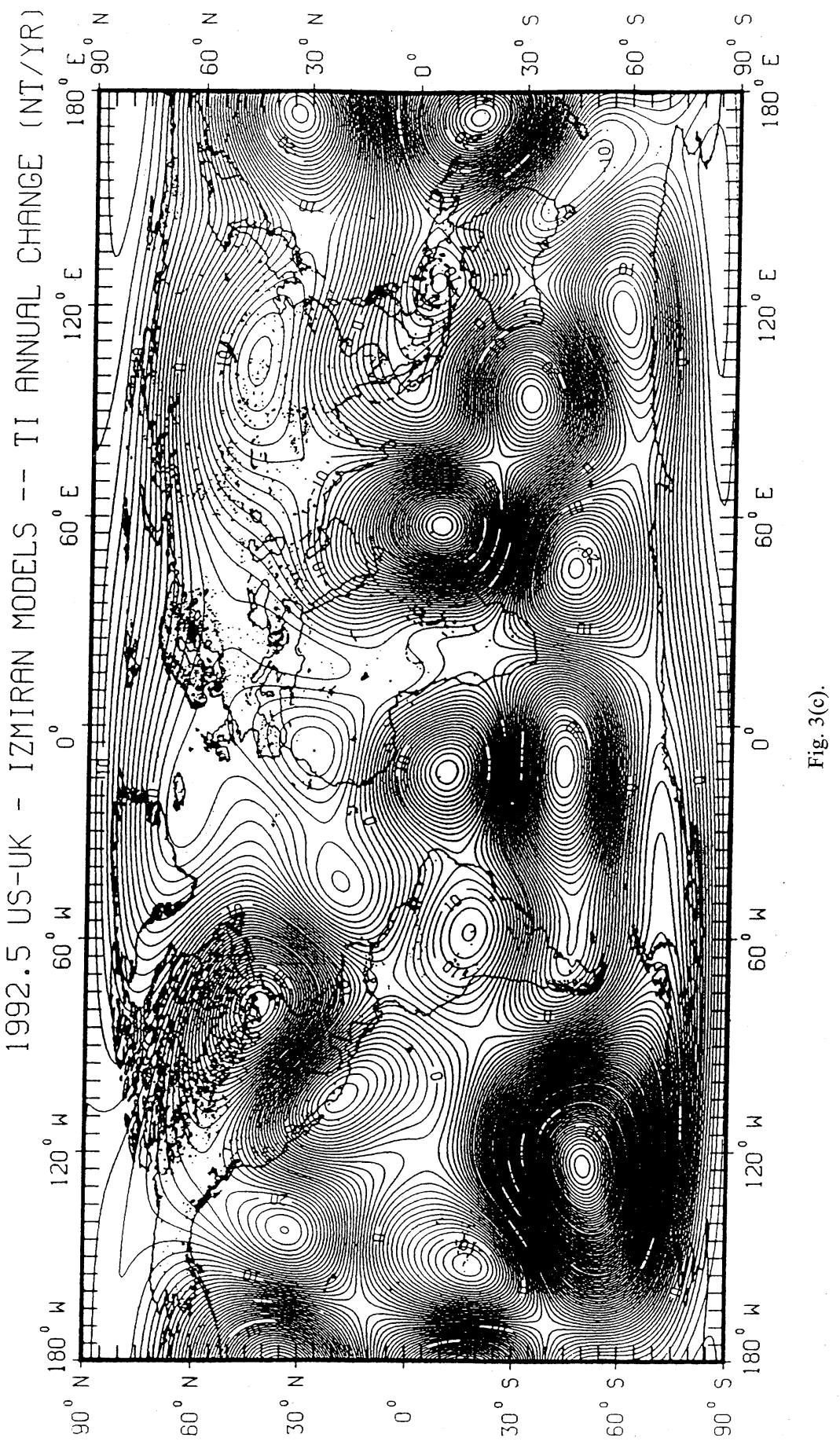


IZMIRAN and US/UK models should receive less weight than the USGS model and the two NASA models for epoch 1985.

Statistics with respect to a globally distributed, post-1985 (1985.0 to 1989.9) global Project MAGNET data set of 29,535 total intensity observations are given in Table 2. These statistics reflect the ability of each DGRF-85 candidate model to accurately characterize the geomagnetic field over the 5-year span for which the DGRF-85 model is expected to be valid. The order of presentation of the model statistics in the table reflect the relative ranking of the models as measured by this data set. The IZMIRAN model which used no Project MAGNET data fairs the worst, while the NASA-DS model, which is distinguished by the fact that it is the only model that uses DE-2 data, is in the best overall agreement with the Project MAGNET data, with an unusually small disagreement in the mean of only-0.6. Except for variations in the mean, however, all models are in good agreement. This assessment applies equally well to main field and secular variation models, since both were used simultaneously to generate the results in Table 2.

At the 1990.0 epoch, the USGS, US/UK, and IZMIRAN models agree very well with each other in the Northern Hemisphere but disagree with both NASA models in central Asia and the eastern Arctic Ocean. Apparently, a small amount of post-1985.0 central Asia land survey data were used to improve the NASA models. In the Southern Hemisphere, all models disagree slightly in the Indian Ocean, while the US/UK model shows a substantial deviation in the south central Pacific Ocean. The IZMIRAN model shows a substantial deviation in the south central Atlantic Ocean as well as a somewhat less pronounced deviation in the southeastern Pacific Ocean. These deviations are again attributable to lack of observatory data in those regions which cause secular variation modeling errors if no attempt is made to supplement the observatory data to maintain control where regional voids in data exist. Some supplemental control data from a-priori models were used by IZMIRAN which did help to some degree particularly for the 1992.5 predictive secular variation model, while the US/UK 1992.5 secular variation model appears to be out of control in the south central Pacific in comparison to the other two models. However, this was not the case for the $1987.5 \mathrm{US} / \mathrm{UK}$ model as can be seen in Fig. 4.

Before deciding on the relative weighting among the models for the 1990.0 epoch main field IGRF model and the 1992.5 epoch secular variation field IGRF model, it is useful to examine these models against recently obtained POGS total intensity data collected between February 10 and March 1, 1991. This data has not been corrected for ionospheric or magnetospheric effects nor has it been selected for low $K_{p}$ indices (i.e., all $K_{p}$ indices are represented). Other than editing the data for transient spikes and correcting for POGS clock bias and drift relative to universal time (UT) using timing pulse calibration data, nothing has

Table 2. Project MAGNET (1985.0-1989.9) TI residuals WRT candidate models (nT).

\begin{tabular}{lllllll}
\hline & \multicolumn{2}{c}{ Model } & Mean & Std & RMS \\
\hline IZMIRAN & $1985 \mathrm{MF}+$ & IZMIRAN & $1987.5 \mathrm{SV}$ & -27.0 & 84.0 & 88.0 \\
US/UK & $1985 \mathrm{MF}+$ & US/UK & $1987.5 \mathrm{SV}$ & -14.0 & 83.0 & 84.0 \\
USGS & $1985 \mathrm{MF}+$ & USGS & $1987.5 \mathrm{SV}$ & -18.0 & 81.0 & 83.0 \\
NASA-S & $1985 \mathrm{MF}+$ & NASA & $1987.5 \mathrm{SV}$ & -15.0 & 80.0 & 82.0 \\
NASA-DS & $1985 \mathrm{MF}+$ & NASA-DS & $1987.5 \mathrm{SV}$ & -0.6 & 82.0 & 82.0 \\
\hline
\end{tabular}




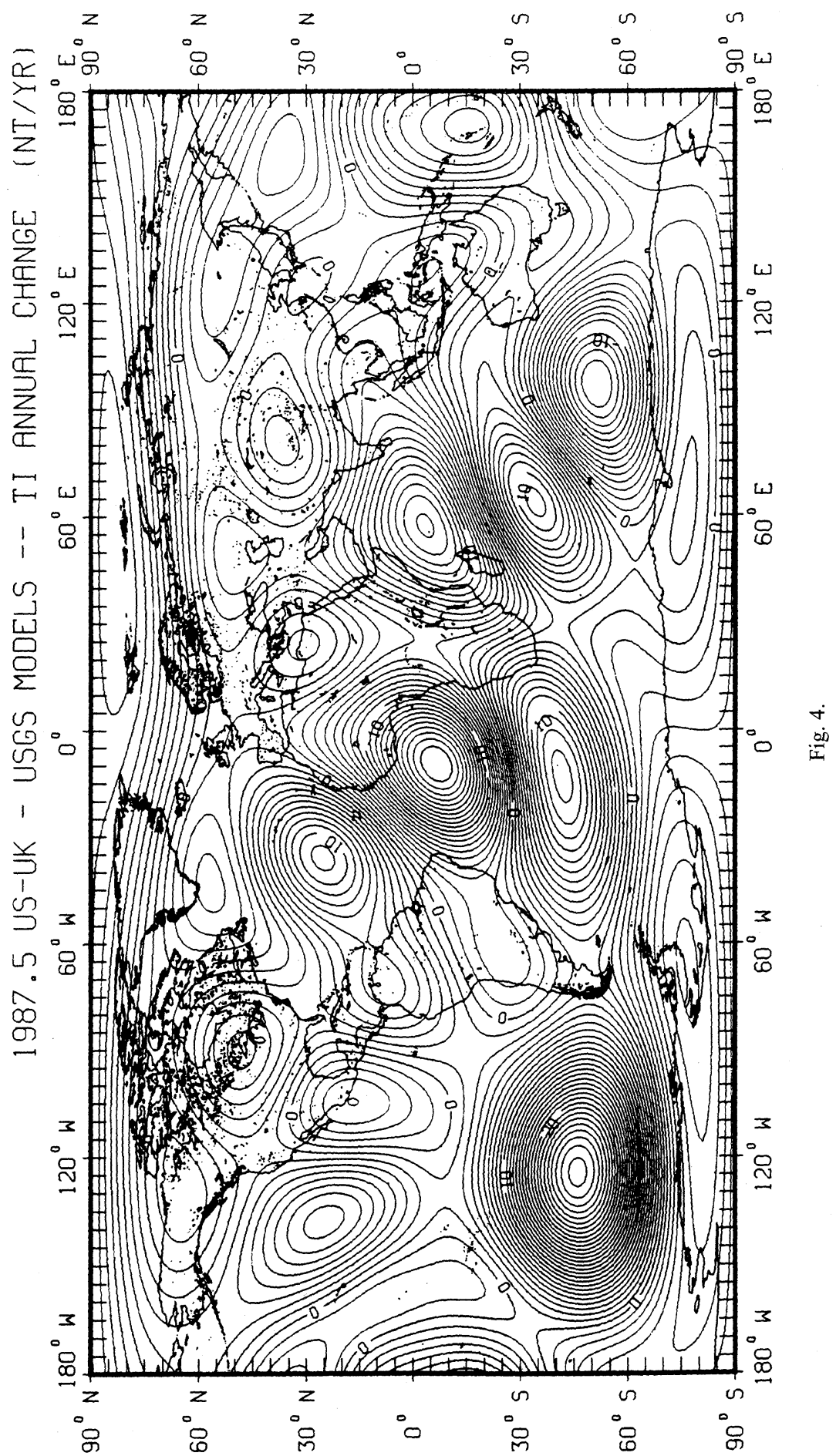




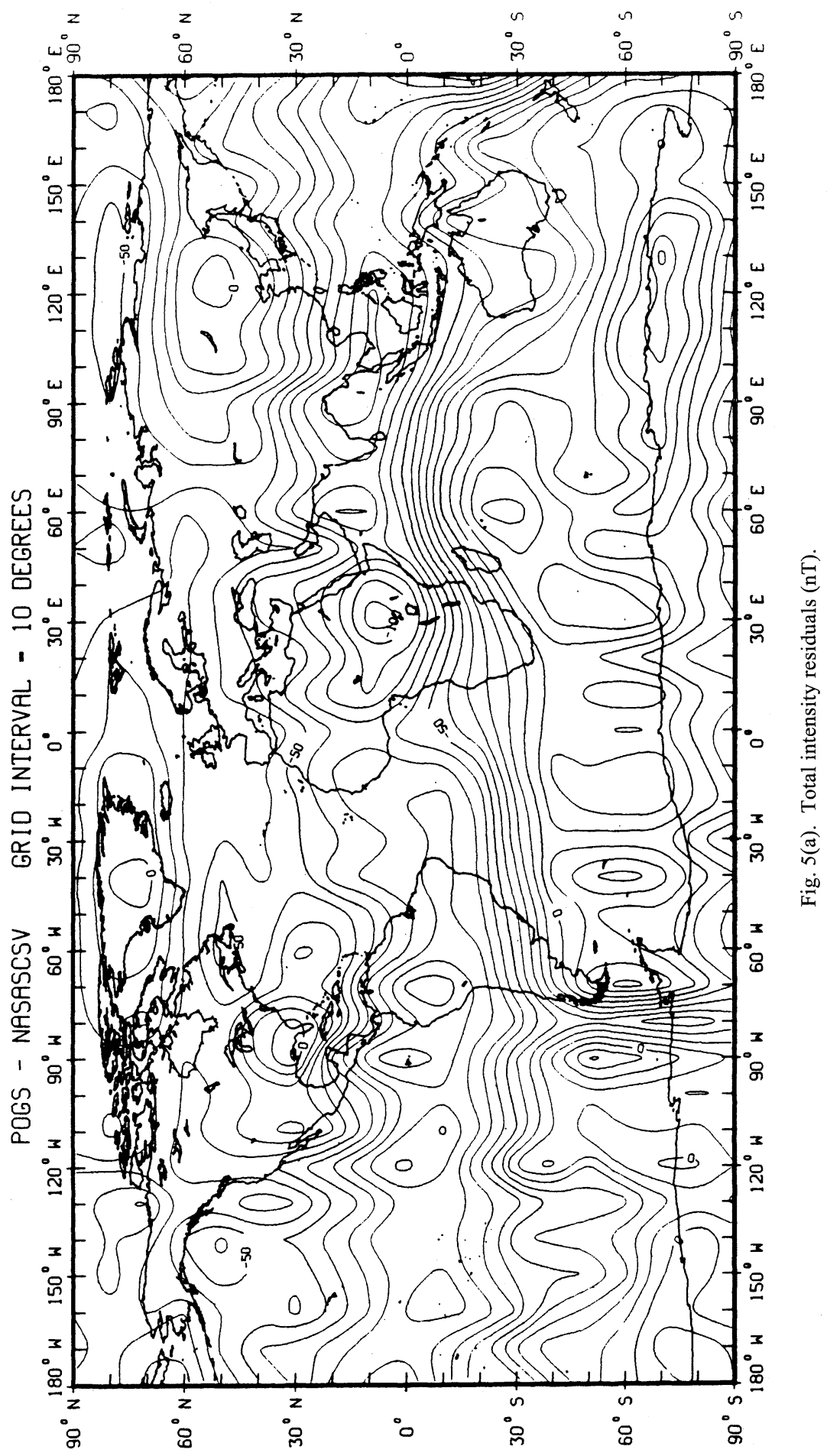




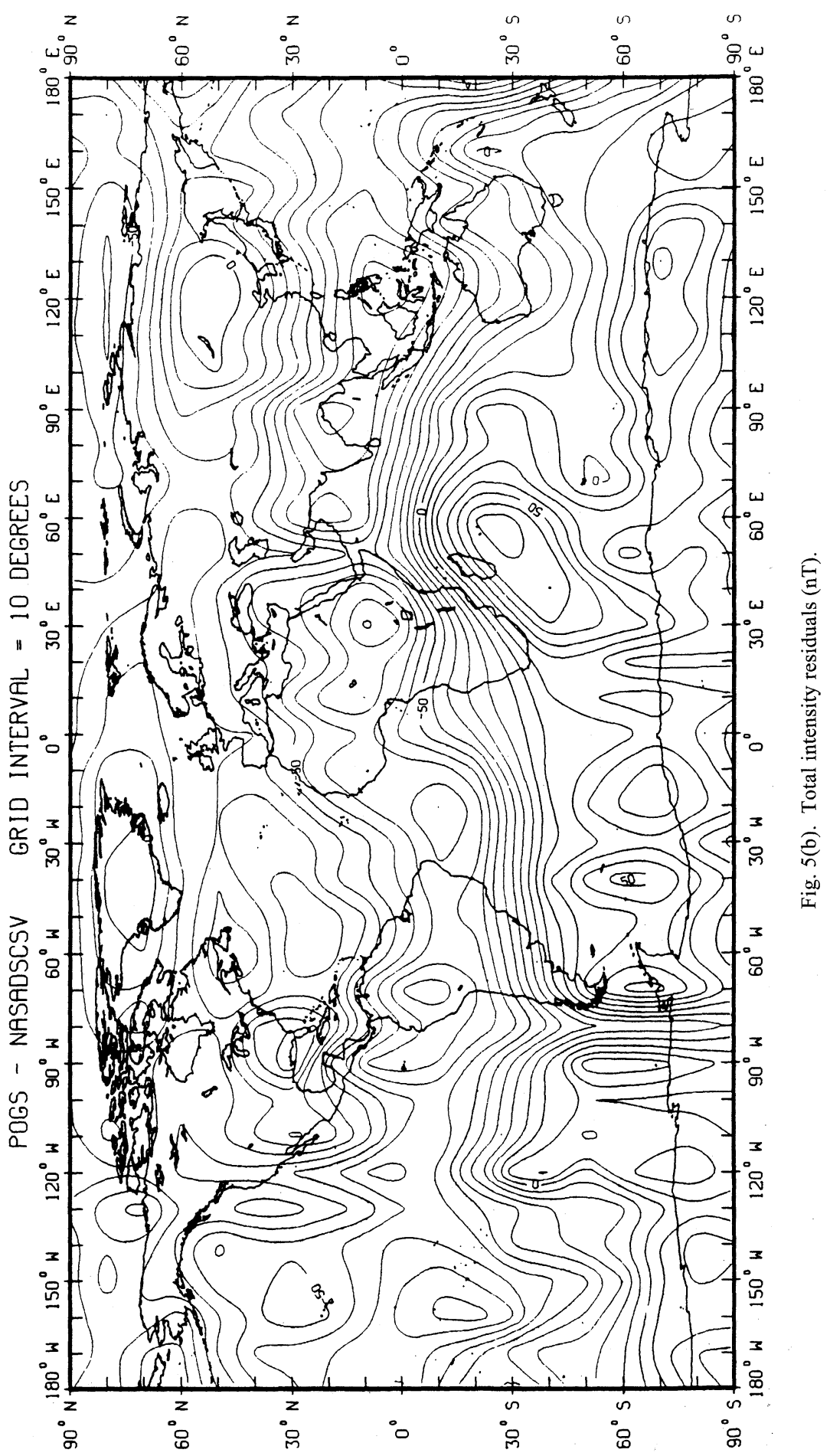




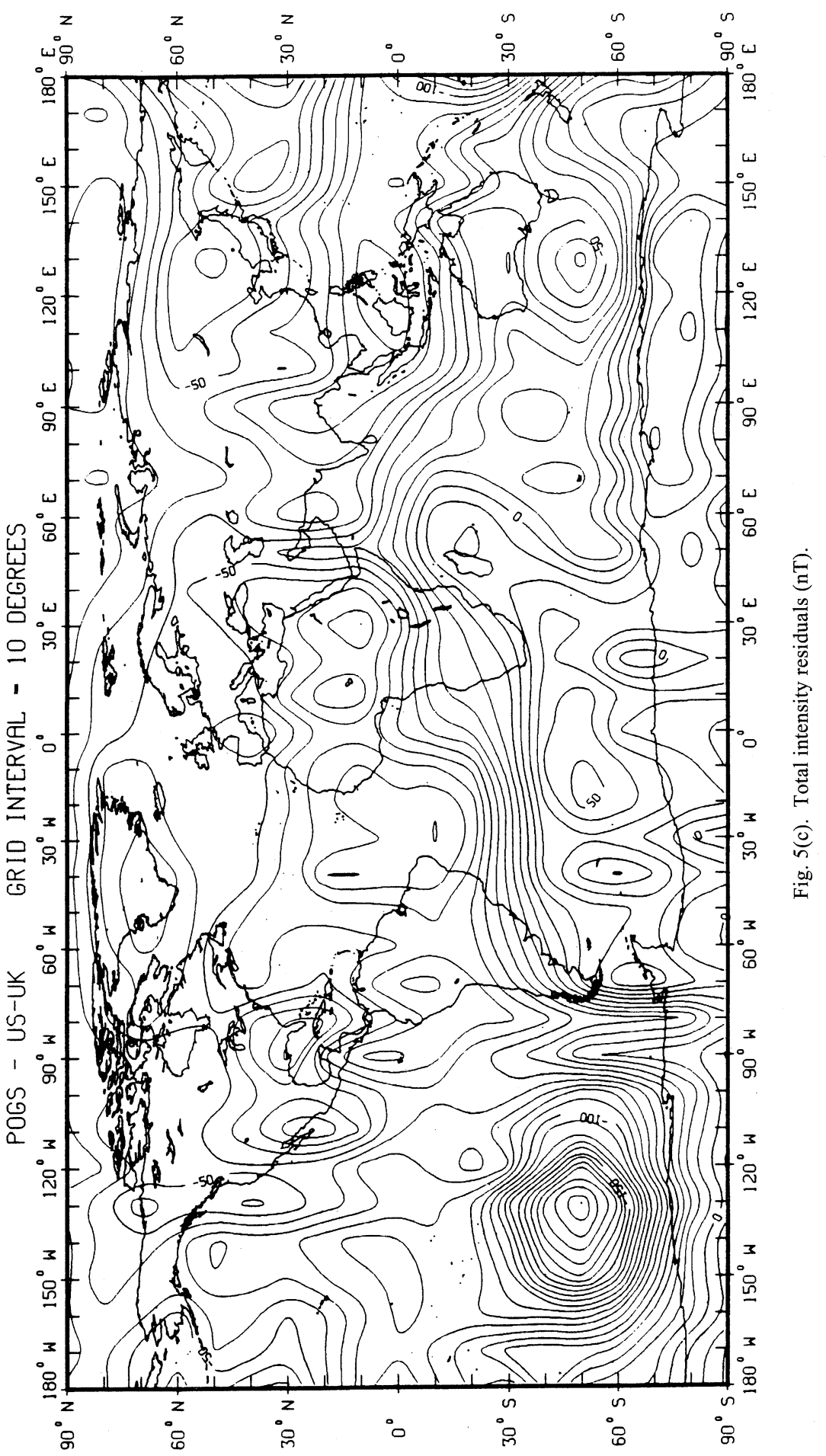




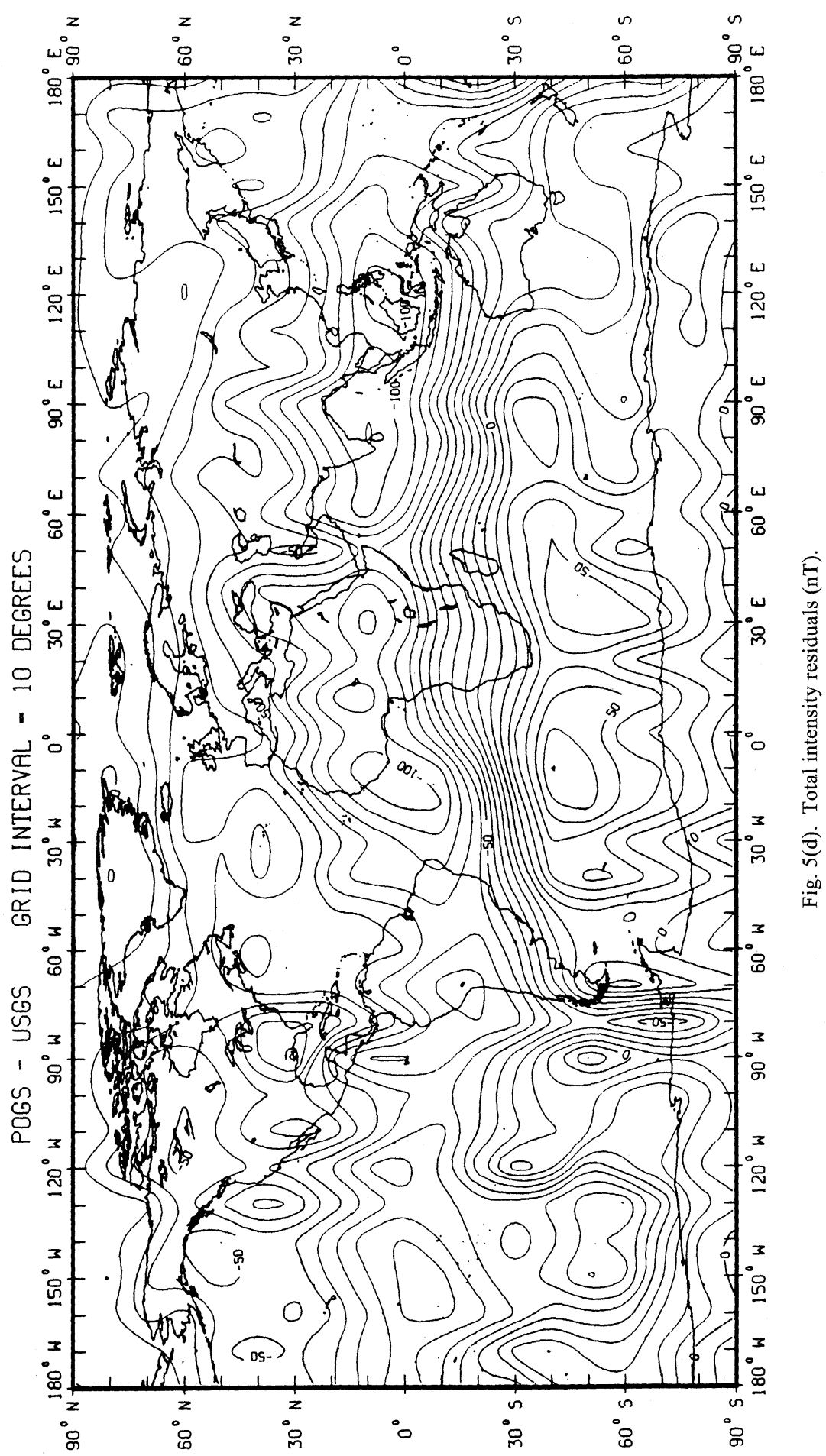




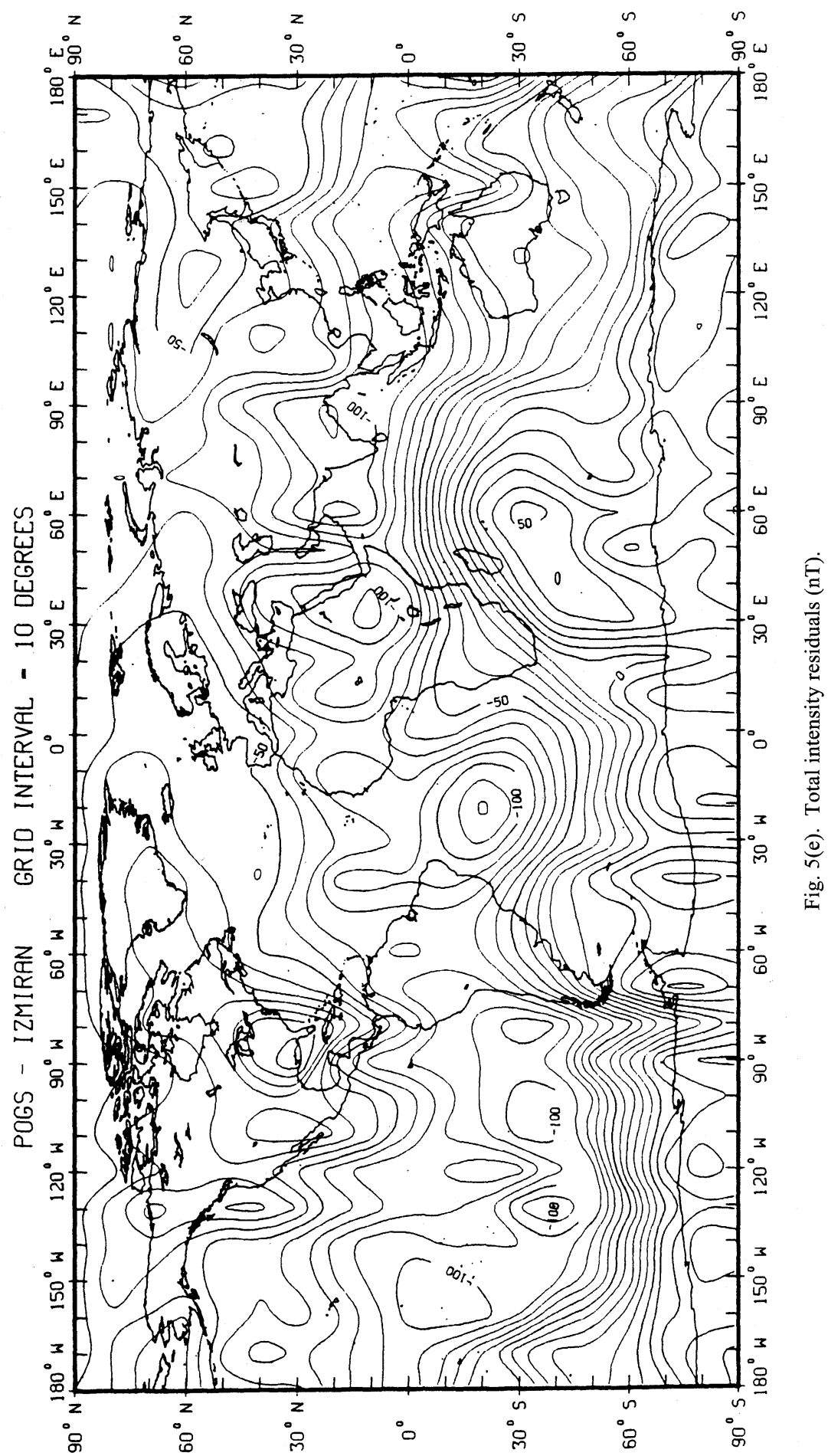




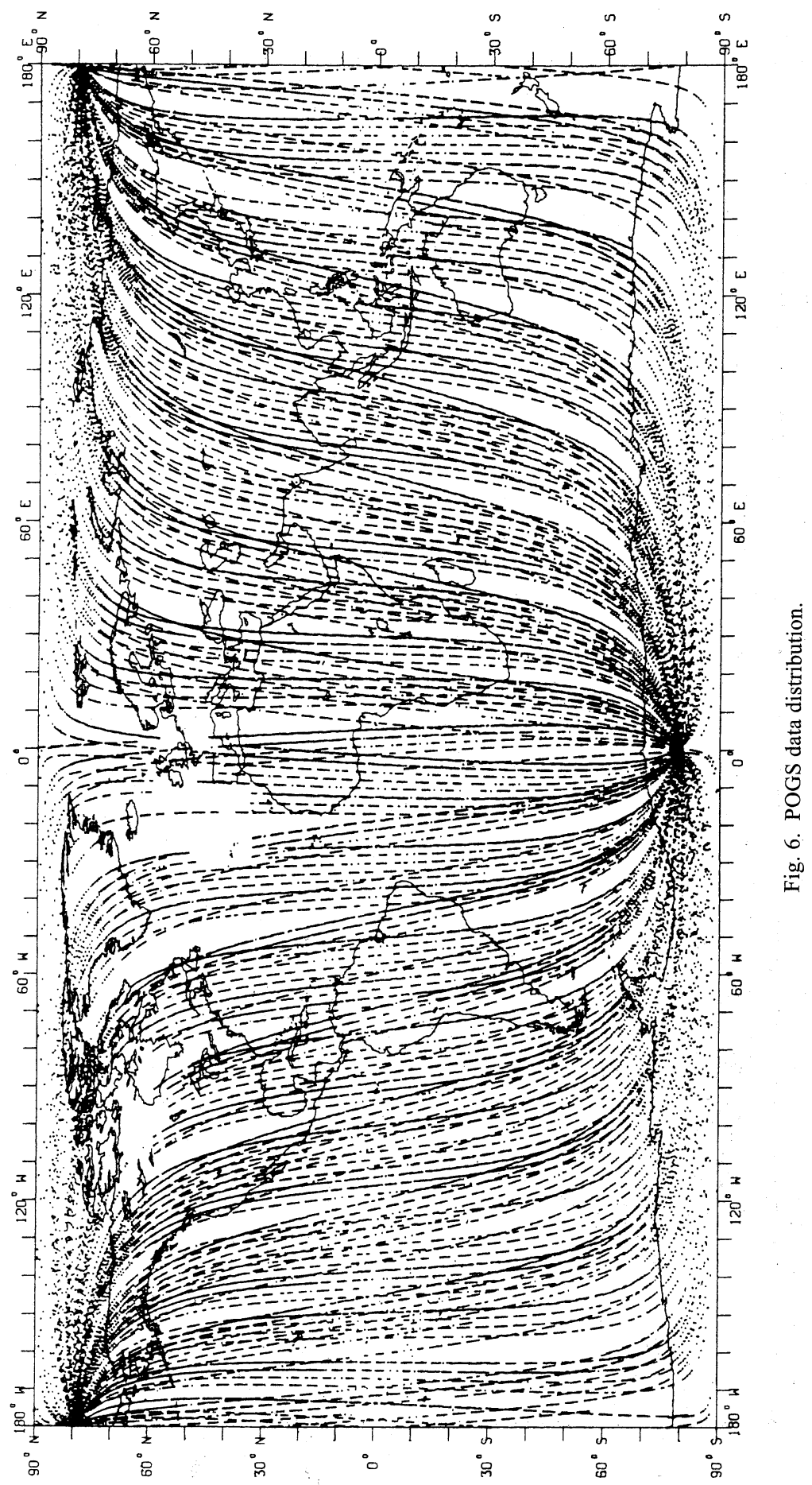


been done to the POGS data. Figures 5(a) through 5(d) show total intensity residuals relative to POGS data for each model at the 1991.1386 epoch of the data. These residuals were used to generate a uniform 10 degree grid which was then contoured at a $10 \mathrm{nT}$ contour interval. The anomaly in the southern hemisphere between $70^{\circ} \mathrm{W}$ and $90^{\circ} \mathrm{W}$ below $60^{\circ} \mathrm{S}$ is an artifact resulting most probably from ionospheric noise in the POGS data in that region and is not due to the candidate models. The data distribution is given in Fig. 6 .

The figures show that the US/UK model compares extremely well (given that this POGS data set is not completely reduced) everywhere except in the south central Pacific where the secular variation model, as expected, is causing problems. The USGS model also compares well except for some minor discrepancies in West Africa and in Indonesia. The IZMIRAN model shows several small discrepancies in the South Pacific, the South Atlantic, East Africa, and India. The NASA-S model (NASASCSV), which uses the USGS 1992.5 secular variation model, shows excellent agreement everywhere except for a small difference in East Africa. The best overall model, however, is the NASA-DS model (NASADSCSV), which also uses the USGS 1992.5 secular variation model. This model is in good agreement everywhere with POGS data with no exceptions. Note also that in central Asia both NASA models agree perfectly with the POGS data. Further POGS data reduction would most likely improve the comparison for all models. Global statistics for the POGS total intensity residuals relative to each candidate model at the epoch of the data is given in Table 3 . There is a clear negative bias appearing in the Mean column of the table. This bias is in large part due to the partially calibrated status of the POGS data. For example, the $7 \mathrm{nT}$ bias calibration correction was not applied to this bias, indicating that there are significant differences among the models in this respect. Otherwise, on a global scale at least, there is very little difference among them. They all exhibit about the same standard deviation, while the mean and Root-Mean-Square (RMS) errors reflect the bias differences among the models. The models are listed in Table 3 in order of increasing agreement with the data.

Table 3. POGS TI residuals WRT candidate models at 1991.1386 (nT).

\begin{tabular}{lllllll}
\hline \multicolumn{3}{c}{ Model } & & Mean & Std & RMS \\
\hline IZMIRAN & $1990 \mathrm{MF}+$ & IZMIRAN & $1992.5 \mathrm{SV}$ & -42.6 & 49.9 & 65.6 \\
US/UK & $1990 \mathrm{MF}+$ & US/UK & $1992.5 \mathrm{SV}$ & -35.9 & 48.9 & 60.7 \\
USGS & $1990 \mathrm{MF}+$ & USGS & $1992.5 \mathrm{SV}$ & -30.9 & 48.2 & 57.3 \\
NASA-S & $1990 \mathrm{MF}+$ & USGS & $1992.5 \mathrm{SV}$ & -29.8 & 45.5 & 54.4 \\
NASA-DS & $1990 \mathrm{MF}+$ & USGS & $1992.5 \mathrm{SV}$ & -22.5 & 47.6 & 52.6 \\
\hline
\end{tabular}

Table 4. Relative weighting of DGRF/IGRF candidate models.

\begin{tabular}{lccccc}
\hline & US/UK & NASA-S & NASA-DS & USGS & IZMIRAN \\
\hline DGRF/MF - 85 & $21 \%$ & $0 \%$ & $30 \%$ & $27 \%$ & $21 \%$ \\
IGRF/MF - 90 & $17 \%$ & $0 \%$ & $36 \%$ & $29 \%$ & $17 \%$ \\
IGRF/SV - 92.5* & $33-1 / 3 \%$ & - & - & $33-1 / 3 \%$ & $33-1 / 3 \%$ \\
\hline
\end{tabular}

*Everywhere except the south central Pacific where the US/UK model should be given zero weight while the other two models receive equal weight. 


\section{Conclusion}

In view of the foregoing analysis/evaluation, some of which has been subjective in nature, the recommended weighting of the candidate models is indicated in Table 4. In that table, we have kept the better of the two NASA models, NASA-DS, and given zero weight to the other. Also, it is recommended that all candidate 1992.5 secular variation models be given equal weight $33-1 / 3 \%$, except in the south central Pacific (i.e., between $90^{\circ} \mathrm{S}$ to $0^{\circ}$ in latitude and between $170^{\circ} \mathrm{E}$ to $90^{\circ} \mathrm{W}$ in longitude) where the US/UK candidate should be given zero weight while the IZMIRAN and USGS models should receive equal weight.

\section{REFERENCES}

Coleman, R. J., Project MAGNET high-level vector survey data reduction, NASA Conference Publication 3153, edited by R. A. Langel, 1992.

LANGEL, R. A., J. R. RidGWAY, M. SUgIURA, and K. MAEZAURD, The geomagnetic field at 1982 from DE-2 and other magnetic field data, J. Geomag. Geoelectr., 40, 1103-1127, 1988.

Quinn, J. M., R. J. Coleman, M. R. PecK, and S. E. LAUber, The joint US/UK 1990 epoch world magnetic model, NAVOCEANO Technical Report \#304, 1991. 